\title{
Research of New Machining Method of Skew Bevel Gears Based on Generation Line
}

\author{
http://dx.doi.org/10.3991/ijoe.v9iS4.2592 \\ Zhaojun Yang ${ }^{1}$, ${ }^{*}$ Baichao Wang ${ }^{1,2}$, Yankun Wang ${ }^{1}$,Yujiang Zhu ${ }^{2}$, Jing Wang ${ }^{2}$, Ying Wang ${ }^{2}$ \\ ${ }^{1}$ Jilin University, Changchun, Jilin, China \\ ${ }^{2}$ Changchun Institute of Equipment and Process, Changchun, Jilin, China
}

\begin{abstract}
According to generating principle of spiral bevel gear and space meshing theory, formation theory of generation line of tooth surface about skew bevel gears is studied. A new processing method of tooth surface with the generation line as chord of face circular cutters is put forward. Moving process model of milling processing with skew bevel gears is built, and profile of the gears can be machined using three axes linkage method based on the model. Machining test of the gears is carried out on experiment platform designed. Furthermore, 3D points cloud model of tooth surface are calculated in light of mathematical model of the tooth surface which has been established, and datum of mesh nodes on actual tooth surface are collected. Then surface errors is evaluated by normal vector equation of the tooth surface which has been developed. Finally, this method is proved to be effective and feasible.
\end{abstract}

Index Terms-skew bevel gears. generation line. mathematical model of tooth surface. machining experiments

\section{INTRODUCTION}

Spiral bevel gears are needed to transfer power and motion between intersecting axes and are widely used in the equipments of aviation, navigation and national defense and mechanical products such as vehicles, machine tools, engineering mechanics[1]. Skew bevel gears are as a part of spiral bevel gears and have all advantages of spiral bevel gears. In the field of gear manufacture at present, design and manufacture process of tooth surface about spiral bevel gear are very complex and the control of quality is very difficult[2]. So spiral bevel gears are a research focus in gear manufacture field[3].

Accordance with the principle of gear engagement, tooth surface of spiral bevel gear should be tooth surface with spherical involute. However, the existing processing technology is performed by using engineering approximation method[4]. So there are theoretical errors on the tooth surfaces. First, transmission ratio is not constant; Second, modification and adjustment of tooth surfaces are complex; Finally, designing and manufacturing need to take a longer period and gears can not be interchanged unless in the same batch. Therefore, in order to reduce to effect of the error, the parameters of machine tools and cutting tool need to be modified and improved continuously[5].

The new method that is put forward can be used to process ideal spherical involute spiral bevel gears that the transmission ratio is constant and gears can be interchanged even in different batches. This method makes the calculation and adjustment of machine tools settings relatively simple, the processing efficient relatively high. It is proved to be effective and feasible by the experiments.

\section{THE GENERATION PRINCIPLE AND MATHEMATICAL MODELING OF SKEW BEVEL GEARS}

There is assumed a sphere which is setting radius dimension as $\mathrm{R}$ and a base cone which culmination and the sphere center coincide, as shown in figure1. The base cone and the great circle of a sphere-a plane $Q$ are tangent to a line. When the base cone is fixed, the plane $Q$ rotate around the base cone and they keep tangency all along. Under the condition of the above expression, the movement of the plane $\mathrm{Q}$ relative to the base cone is what is needed pure roll for generating spherical involute. If there is a straight line ML on the plane Q. In the expansion, the straight line ML can spread a curved surface, while the curved surface is then involute helicoids.

As shown in figure. 2. Base cone angle $\delta b$ generatrix of small end about base cone $\mathrm{Rb}$ base cone circle spreading angle $\varphi$ plane $Q$ spreading angle $\gamma$. Fixed coordinate systems $\mathrm{S}(\mathrm{o}-\mathrm{x}, \mathrm{y}, \mathrm{z})$ are rigidly connected to the gear blanks. In this systems, origin oland $\mathrm{x} 1-\mathrm{y} 1$ plane coincide with center of cone and bottom of base cone respectively; At the same time, Matrix M1t provides the coordinate transformations from system $\mathrm{S} 1$ into the top coordinate system St(ot-xt,yt,zt) by offsetting A along the axis z1; And matrix Mts defines the relation between the stationary coordinate systems St and $\mathrm{Ss}(\mathrm{os}-\mathrm{xs}, \mathrm{ys}, \mathrm{Zs})$, in which coordinate systems Ss rotate $\varphi$ on the axis zt ; Afterward Matrix Msb performs the coordinate transformations from system $\mathrm{Ss}$ into the top coordinate system $\mathrm{Sb}(\mathrm{ob}-\mathrm{xb}, \mathrm{yb}, \mathrm{zb})$ by moving $\pi / 2-\delta b$ around the axis ys, at the same time axis $\mathrm{xb}$ and origin ob coincide with the line of base cone and the plane $\mathrm{Q}$ respectively[6]; Finally, Mbq denote the transformations from $\mathrm{Sb}$ into $\mathrm{Sq}(\mathrm{oq}-\mathrm{xq}, \mathrm{yq}, \mathrm{zq})$ by revolving $\gamma$ around $\mathrm{zb}$ connected to the plane $\mathrm{Q}$.

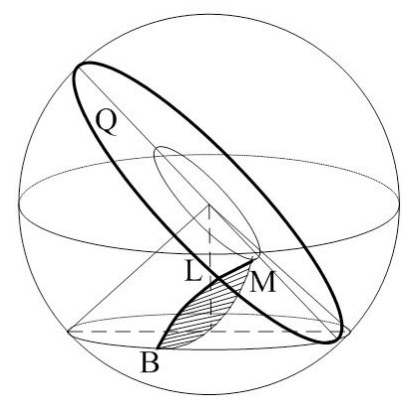

Figure 1. Formation Principle Tooth Surface 


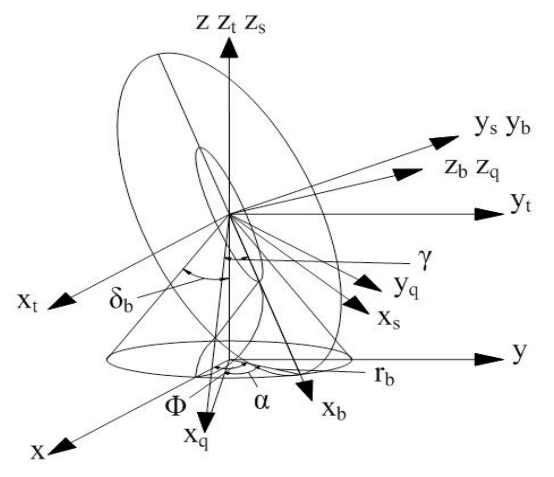

Figure 2. Coordinate Transform

In the spreading process, a cluster of tracing line that are formed by generation line ML make up involute helicoids. In the coordinate systems $\mathrm{S}$, the value of the generation line ML can be acquired by Coordinate Transform from coordinate systems $\mathrm{Sq}$ [7]. When parameter $\varphi$ continuous change, In the coordinates system $\mathrm{S}(\mathrm{o}-\mathrm{x}, \mathrm{y}, \mathrm{z})$ the mathematical model of a point on the Tooth-surface can be performed by applying the following equation:

$$
\left[\begin{array}{c}
\mathbf{x} \\
\mathbf{y} \\
z \\
\mathbf{t}
\end{array}\right]=\mathbf{M}_{1 \mathrm{t}} \mathbf{M}_{\mathrm{ts}} \mathbf{M}_{\mathrm{sb}} \mathbf{M}_{\mathrm{bq}}\left[\begin{array}{c}
\mathbf{x}_{\mathrm{q}} \\
\mathbf{y}_{\mathbf{q}} \\
\mathbf{z}_{\mathbf{q}} \\
\mathbf{t}_{1}
\end{array}\right]
$$

Where,

$$
\mathbf{M}_{\mathbf{b q}}=\left[\begin{array}{cccc}
\cos (\psi) & \sin (\psi) & 0 & 0 \\
-\sin (\psi) & \cos (\psi) & 0 & 0 \\
0 & 0 & 1 & 0 \\
0 & 0 & 0 & 1
\end{array}\right]
$$

$$
\begin{gathered}
\mathbf{M}_{\mathbf{s b}}=\left[\begin{array}{cccc}
\cos \left(\pi / 2-\delta_{\mathbf{b}}\right) & 0 & \sin \left(\pi / 2-\delta_{\mathbf{b}}\right) & 0 \\
0 & 1 & 0 & 0 \\
-\sin \left(\pi / 2-\delta_{\mathbf{b}}\right) & 0 & \cos \left(\pi / 2-\delta_{\mathbf{b}}\right) & 0 \\
0 & 0 & 0 & 1
\end{array}\right] \\
\mathbf{M}_{\mathrm{ts}}=\left[\begin{array}{cccc}
\cos (\phi) & -\sin (\phi) & 0 & 0 \\
\sin (\phi) & \cos (\phi) & 0 & 0 \\
0 & 0 & 1 & 0 \\
0 & 0 & 0 & 1
\end{array}\right]
\end{gathered}
$$

$$
\mathbf{M}_{1 \mathbf{t}}=\left[\begin{array}{cccc}
1 & 0 & 0 & 0 \\
0 & 1 & 0 & 0 \\
0 & 0 & 1 & \mathbf{A} \\
0 & 0 & 0 & 1
\end{array}\right]
$$

When big circle(plane Q) pure roll, the circular arc that base cone bottom circle is bypassed by big circle is same length. In the cartesian coordinate system, the vector equation of tooth surface about circle spreading angle $\varphi$ and polar Radius $\rho$ is shown :

$$
\mathbf{r}^{\mathrm{I}}=\mathbf{x}(\phi, \rho) \mathbf{i}+\mathbf{y}(\phi, \rho) \mathbf{j}+\mathbf{z}(\phi, \rho) \mathbf{k}
$$

\section{ANALYSIS OF SKEW BEVEL GEARS CUTTING MOVEMENT}

Based on the above expression, profile of gears surface is formed accurately in accord with surface generating principle by the milling cutters which processes gears along tracing of generating line ML that is also generation line, if the generation line is as chord of face circular milling cutters. The plane Q spread on the base cone is equal to that plane $\mathrm{Q}$ turn around a center with angular velocity $\omega(\mathrm{b})$ and rotate around axis of the base cone at the angle rate of $-\omega(\mathrm{t})$ simultaneity, namely, the plane $\mathrm{Q}$ relative to of the base cone move with angular velocity $\omega(\mathrm{b})-\omega(\mathrm{t})$. When the base cone rotate $\omega(\mathrm{t})$ around axis of itself, spreading movement of tooth surface established can be decomposed that: base cone rotates with angular velocity vector $\omega t$, at the same time generation line $\mathrm{ML}$ on the plane $\mathrm{Q}$ rotate around itself axis at the angle rate vector of $\omega b$ relative to space coordinate. So there is a relationship between them:

$$
\frac{\omega_{b}}{\omega_{t}}=\sin \delta_{b}
$$

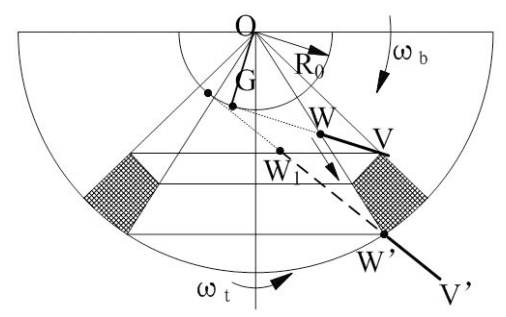

Figure 3. Analysis of Cutting Movement

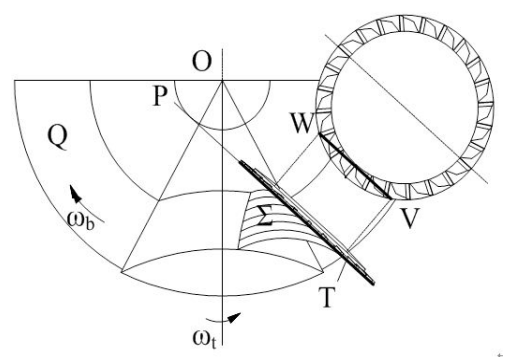

Figure 4. Cutting Movement of Circular Milling Cutters

As shown in figure 3, according to above motion relationship, chord of face circular milling cutters rotate with angular velocity $\omega(\mathrm{b})$ following plane $\mathrm{Q}$. When generation line is in line segment $\mathrm{WV}$, the chord cut in small end of bevel gear. When the chord moves to W1, it shows that the cutter will cut into root cone, and the overcut will happen. Tool edge rotates following Q. Meanwhile, it moves along chord direction. So the motion direction of the tool edge is along line segment $\mathrm{OW}^{\prime}$ in order to avoid overcut. Because circular milling cutters rotate with angular velocity $\omega(\mathrm{b})$ the velocity of perpendicular to line OW direction is: 


\section{Research of New Machining Method of SKew BeVel Gears Based on Generation Line}

According to right triangle OGW, the velocity of OW direction is shown:

$$
\mathbf{v}_{\text {ow }}=\frac{\mathbf{R}_{0} \cdot \varpi_{\mathbf{b}} \cdot \sin \varpi_{b} \mathbf{t}}{\cos ^{2} \varpi_{b} t}
$$

As shown in figure 4 , circular milling cutters which is selected feature simple structure. Main cutting edge of milling cutters is in the same plane and the plane is vertical to tool shaft. The main cutting edge in high speed rotation form rotary plane $\Sigma$, chord WV in which can be as generation line to realize motion of tooth surface generation.

\section{MACHINE TOOL DESIGN OF SPIRAL BEVEL GEARS}

Initial position relation of chord of circular milling cutters and workpiece are determined, through adjust position of worktable $\mathrm{X}, \mathrm{Y}$ direction and degree of $\mathrm{Z}$ direction as well as change angle of inclined rotary table $C$ and level rotary table $\mathrm{B}$ based on base cone angle $\delta \mathrm{b}$. When spiral bevel gears are processed, the work-shaft and level rotary table rotate with angular velocity $\omega t$ and $\omega \mathrm{b}$ respectively to satisfy the equation 4 that ensure the strict proportion of the tool shaft and the workpiece movement so as to realize tooth surface spread correctly. Movement of the tool shaft and workpiece are as above mentioned. Meanwhile, Y axis move with angular velocity based on equation 5 to avoid overcut and complete feed drive. Therefore, the relation of three Axes linkage is composed with workshaft. Level rotary table rotation and $\mathrm{Y}$ axis motion to realize milling of skew bevel gears.

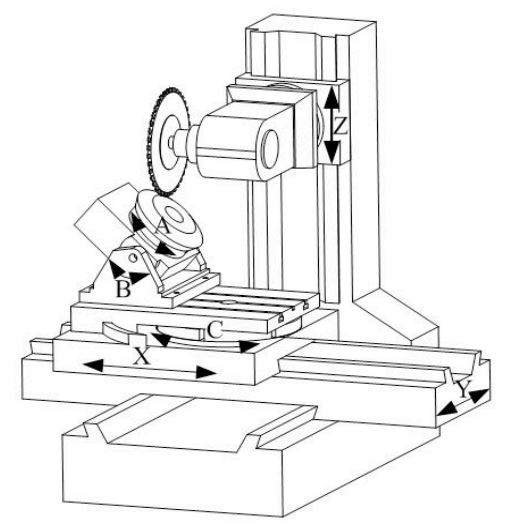

Figure 5. 3D Model of Machine Tool

Initial position of machine tool is adjusted according to parameter of gear manufactured, including pressure angle $\alpha$, pitch angle $\delta$, mean spiral angle $\beta$, base cone angle $\delta b$, root cone angle $\delta f$ face cone angle $\delta a$, face width $b$. Finally, NC program is designed to accomplish cutting process of gears.

\section{EXPERIMENTAL VERIFICATION OF MILLING AND DETECTION}

In this milling experiment, the material of milling cutter designed is cemented carbide, cutter Diameter is $350 \mathrm{~mm}$, tooth number is 12 , length of cutter tooth is $13 \mathrm{~mm}$, the rake angle of main cutting edge is $5^{\circ}$, Celief angle of pair cutting edge is $6^{\circ}$. The material of a pair skew bevel gears is aluminum alloy. Main parameter of pinion and gearwheel are given in table 1.
When gearwheel is processed, milling cutter move from small end to big end first so that one side of tooth surface can completed. Another side however from big end to small end. On the contrary, when pinion was processed, milling cutter move from big end to small end so that one side of tooth surface can completed. Another side but from small end to big end.

TABLE I.

GEOMETRY PARAMETERS OF SKEW BEVEL GEARS

\begin{tabular}{|c|c|c|}
\hline Modeling parameters & pinion & $\begin{array}{l}\text { gear- } \\
\text { wheel }\end{array}$ \\
\hline Tooth number $\mathrm{z}$ & 14 & 65 \\
\hline Big end module $\mathrm{m} / \mathrm{mm}$ & 6 & 6 \\
\hline Root cone angle $\delta_{\mathrm{f}} /{ }^{\circ}$ & 11.2171 & 11.2171 \\
\hline Big end pitch circle diameter $\mathrm{D} / \mathrm{mm}$ & 84 & 390 \\
\hline Base cone spiral angle $\beta_{\mathrm{b}} /{ }^{\circ}$ & 35 & 35 \\
\hline Pitch cone angle $\delta /{ }^{\circ}$ & 12.1549 & 77.8451 \\
\hline Pressure angle $\mathrm{a}_{\mathrm{p}} /{ }^{\circ}$ & 22.5 & 22.5 \\
\hline Root cone angle $\delta_{\mathrm{f}}{ }^{\circ}$ & 11.2171 & 11.2171 \\
\hline Face cone angle $\delta_{\mathrm{a}} /{ }^{\circ}$ & 14.5833 & 78.6156 \\
\hline Base cone angle $\delta_{b} /{ }^{\circ}$ & 11.2171 & 64.5777 \\
\hline Face width $\mathrm{b} / \mathrm{mm}$ & 60 & 60 \\
\hline Cutting area $\mu /^{\circ}$ & 9.3744 & 9.5027 \\
\hline Adjusting angle of cutting area $\psi /{ }^{\circ}$ & 0 & 54.0892 \\
\hline Generatrix of big end about base cone $\mathrm{L}_{\mathrm{b} 1} / \mathrm{mm}$ & 199.4992 & 117.1003 \\
\hline $\begin{array}{l}\text { Radius of Tangent Circle about Toothed } \\
\text { Portion } \mathrm{R}_{0} / \mathrm{mm}\end{array}$ & 97.2207 & 49.9587 \\
\hline The Length of generation line $[\mathrm{C}]_{\mathrm{r}} / \mathrm{mm}$ & 52.2233 & 81.0328 \\
\hline Center distance of cutting edge $\mathrm{L}_{\mathrm{N}} / \mathrm{mm}$ & 173.0410 & 170.245 \\
\hline
\end{tabular}

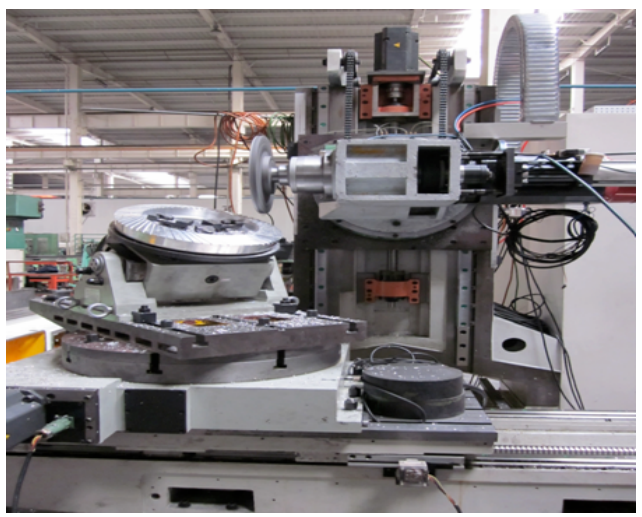

Figure 6. Cutting Processing of Gearwheel

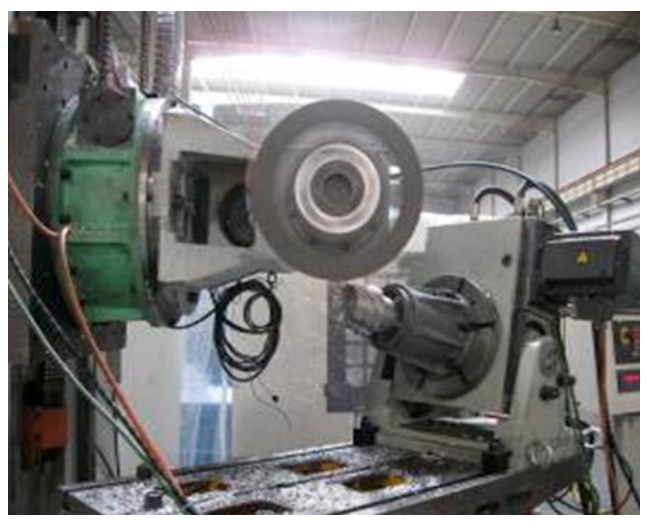

Figure 7. Cutting Processing of Pinion 


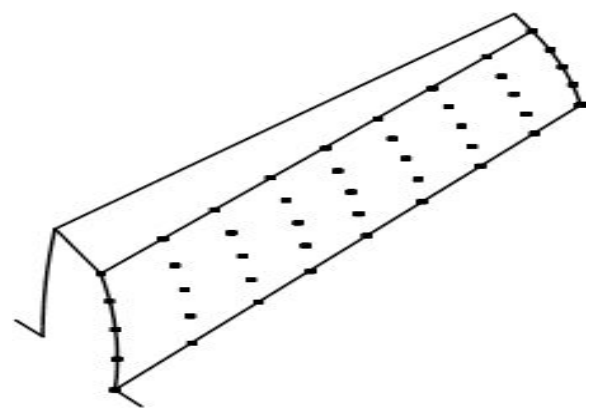

Figure 8. Detection Point

Based on the mathematical model of tooth surface about skew bevel gears, accurate 3D point cloud model of bevel gears are built in matlab. Meanwhile, plan the measuring path on the ideal tooth surface and establish theories coordinate system that is in keeping with measuring-coordinate system. Then, the datum of mesh nodes on the actual tooth surface are collected by coordinate measuring machine, and so these datum of discrete points of actual tooth surface are introducted into matlab system. According to coordinate transformation, spatial position error of discrete points between actual tooth surface and ideal tooth surface is calculated. Finally, tooth surface error of skew bevel gears is evaluated by means of difference surface[9].

Given $(\mathrm{r}+1) \times(\mathrm{s}+1)$ data points $\mathrm{Qk}, \mathrm{l}, \mathrm{k}=0 \ldots \mathrm{r}, \mathrm{l}=0 \ldots \mathrm{s}$, non-uniform $B$-spline surface can be fitted to $3 \times 3$ th power and $(\mathrm{m}+1) \times(\mathrm{n}+1)$ points, namely:

$$
\mathbf{S}(\phi, \rho)=\sum_{i=0}^{n} \sum_{j=0}^{m} \mathbf{N}_{i, 3}(\phi) \mathbf{N}_{j, 3}(\rho) \mathbf{P}_{i, j}
$$

Where, $\mathrm{Ni}, 3(\Phi), \mathrm{Nj}, 3(\rho)$ is B-spline basis function, Pi,j is control points. Derivative of spline curve can get to be known that, partial derivative along $\mathrm{u}$ direction and $\mathrm{v}$ direction respectively are needed in order to get the surface normal. Partial derivative of $u$ direction:

$$
\mathbf{S}_{\phi}(\phi, \rho)=\sum_{i=0}^{n-1} \sum_{j=0}^{m} N_{i, 2}(\phi) N_{j, 3}(\rho) P_{i, j}^{(1,0)}
$$

Where, $\quad \mathbf{P}_{\mathbf{i}, \mathbf{j}}^{(1.0)}=3 \frac{\mathbf{P}_{\mathbf{i}+1, \mathbf{j}}-\mathbf{P}_{\mathbf{i}, \mathbf{j}}}{\phi_{\mathbf{i}+4}-\phi_{\mathbf{i}+1}} \quad$, knot vector: $\rho^{(1)}=\left\{0, \cdots, 0, \rho_{4}, \cdots, \rho_{s-1}, 1, \cdots, 1\right\}, \rho^{(0)}=0$. In the same way, partial derivative of $\mathrm{u}$ direction:

$$
\mathbf{S}_{\rho}(\phi, \rho)=\sum_{i=0}^{n} \sum_{j=0}^{m-1} \mathbf{N}_{i, 3}(\phi) \mathbf{N}_{j, 2}(\rho) \mathbf{P}_{i, j}^{(0,1)}
$$

$\mathbf{S}_{\phi}(\phi, \rho)$ and $\mathbf{S}_{\rho}(\phi, \rho)$ are tangent vector of curved surface along $\mathrm{u}$ and $\mathrm{v}$ direction respectively. Because normal vector of one point on curved surface is perpendicular to tangent vector of any direction by the point, the normal vector equal to cross product of two cross product as follows:

$$
\mathbf{S}_{\phi \times \rho}(\phi, \rho)=\mathbf{S}_{\phi}(\phi, \rho) \times \mathbf{S}_{\rho}(\phi, \rho)
$$

Measuring probe of 3D coordinate measuring machine presets a certain position of initial measuring point in normal direction on the basis of the vector formula 12 . Measuring element mesh nodes on convex and concave of spiral bevel gears are measured in normal direction. The datum of all tooth in turn collecte average a set of numbers[10].

The maximum positive deviation about convex of gearwheel is less than $0.0379 \mathrm{~mm}$, maximum negative deviation while $0.0491 \mathrm{~mm}$. Similarly, the maximum positive deviation about concave of gearwheel is less than $0.0289 \mathrm{~mm}$, maximum negative deviation while $0.0390 \mathrm{~mm}$. The trend of error: convex from small end to big end shown an increasing tendency, maximum deviation is present to top of small end. Concave from small end to big end shown an increasing tendency.

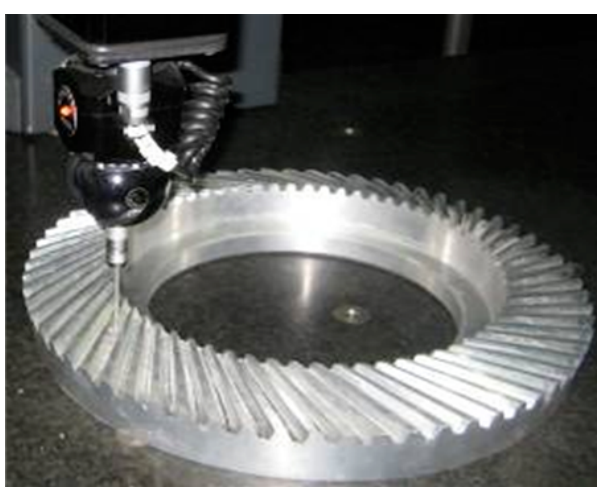

Figure 9. Detection of Gearwheel

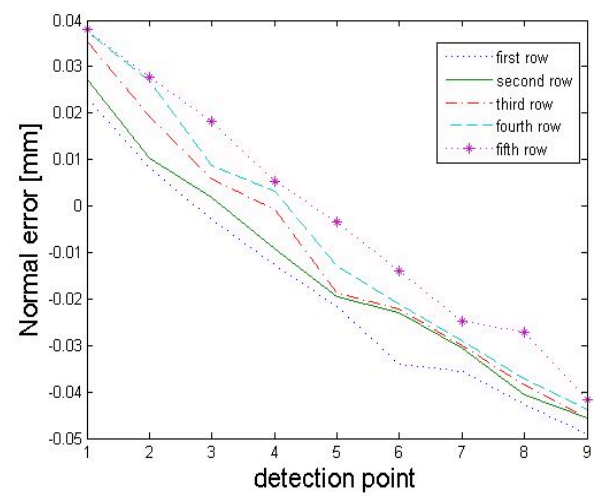

Figure 10. Convex Error of Gearwheel

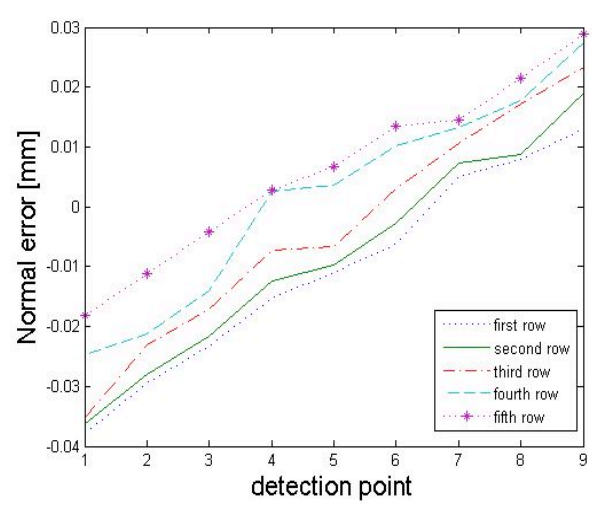

Figure 11. Concave Error of Gearwheel 


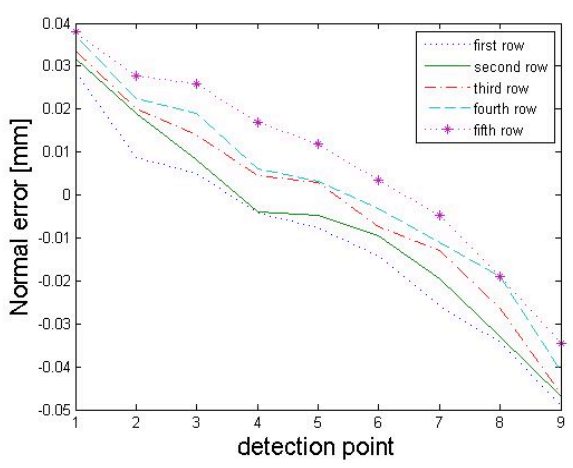

Figure 12. Convex Error of Pinion

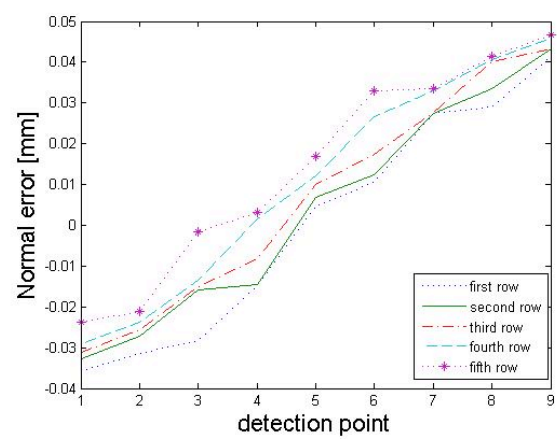

Figure 13. Concave Error of Pinion

The maximum positive deviation about convex of pinion is less than $0.0370 \mathrm{~mm}$, maximum negative deviation while $0.0482 \mathrm{~mm}$, Similarly, the maximum positive deviation about concave of pinion is less than $0.0467 \mathrm{~mm}$, maximum negative deviation while $0.0358 \mathrm{~mm}$. The trend of error: convex from small end to big end showed an increasing tendency, maximum deviation is present to top of small end. Concave from small end to big end showed an increasing tendency, maximum deviation is present to top of small end.

\section{CONCLUSIONS}

Generation line cutting methods is used for skew bevel gears. Namely, the generation line is as chord of face circular milling cutters, the tracing that generation ling spread involute helicoids is just the cutting trace chord of face circular milling cutters. Skew bevel gears without theoretic errors are machined using three axes linkage by this method. The cutting motion and control is greatly simplified by utilizing this method. Machining experiments of a pair of mesh gear are performed by generation line processing method. And then, the measurement and evaluation of the pairs are completed. Detection results :the maximum positive deviation about convex of gearwheel is less than $0.0491 \mathrm{~mm}$. The maximum positive deviation about convex of pinion is less than $0.0482 \mathrm{~mm}$. The experimental results show that this method is feasible and effective.

\section{ACKNOWLEDGMENT}

This project is supported by Research Fund for the Doctoral Program of Higher Education of China (Grant No. 20090061110023), Research Fund for the Doctoral Program of Higher Education of China (Grant No.20120061110087) and Key Program of Technology Development of Jilin Province (Grant No. 20080346).

\section{REFERENCES}

[1] Gonzalez-Perez, Ignacio, Fuentes, Alfonso, Hayasaka, Kenichi, "Analytical determination of basic machine-tool settings for generation of spiral bevel gears from blank data", ASME J. Mech. Des., 132, 2010, pp. 1-11 http://dx.doi.org/10.1115/1.4002165

[2] Faydor L. Litvin, Alfonso Fuentes, Kenichi Hayasaka, "Design,manufacture, stress analysis, and experimental tests of lownoise high endurance spiral bevel gears", Mechanism and Machine Theory ,No. 41, 2006, pp.83-118 http://dx.doi.org/10.1016/ j.mechmachtheory.2005.03.001

[3] Fan Qi, Ronald S. DaFoe, John W. Swanger, "Higher-Order Tooth Flank Form Error Correction for Face-Milled Spiral Bevel and Hypoid Gears", ASME J. Mech. Des., no. 130, 2008, p. 072601

[4] Vilmos Simon, "Generation of Hypoid Gears on CNC Hypoid Generator", journal of mechanical design, Vol.133, No.12, 2011, pp.1-9

[5] Yi-Pei Shih, "A novel ease-off flank modification methodology for spiral bevel and hypoid gears", Mechanism and Machine Theory, 45, 2010, pp.1108-1124 http://dx.doi.org/10.1016/j.mechmac htheory.2010.03.010

[6] Kazumasa Kawasaki, "Analytical and Experimental Tooth Contact Pattern of Large-Sized Spiral Bevel Gears in Cyclo-palloid System", Journal of Mechanical Design, 132, 2010, p.041004 http://dx.doi.org/10.1115/1.4001348

[7] Ying-Chien Tsai, Wei-Yi Hsu, "The study on the design of spiral bevel gear sets with circular-arc contact paths and tooth profiles", Mechanism and Machine Theory, No.43, 2008, pp.1158-1174 http://dx.doi.org/10.1016/j.mechmachtheory.2007.08.004

[8] Jun Wang, Teik C. Lim, Mingfeng Li, "Dynamics of a hypoid gear pair considering the effects of time-varying mesh parameters and backlash nonlinearity", Journal of Sound and Vibration ,No.308, 2007, pp.302-329 http://dx.doi.org/10.1016/j.jsv.2007.07.042

[9] Wang Jun,Wang Xiao Chun,Jiang Hong. "Measurement and compensation of deviations of real tooth surface of spiral bevel gear", Chinese Journal of Aeronautics, Vol.16, No.3, 2003, pp.182186 http://dx.doi.org/10.1016/S1000-9361(11)60181-7

[10] Alexander A. Kist, Andrew D Maxwell," Network Performance and Quality of Experience of Remote Access Laboratories", International Journal of Online Engineering,Vol.8,No.4, pp. 5057,2012

[11] D. Ponta, A. M. Scapolla, P. Buschiazzo, "Survey of RemoteLaboratory Using Service Oriented Architectures", International Journal of Online Engineering, Vol 5, No 1, 2009, pp. 34-39

[12] Euan Lindsay, Steve Murray, Ben Stumpers," A Toolkit for Remote Laboratory Design \& Development", International Journal of Online Engineering, Vol 8, No 1, 2012, pp. 14-19

\section{AUTHORS}

Zhaojun Yang Male, born in 1956, obtained his bachelor's degree in 1982 at Jilin University. In 1995, Professor Yang received his Ph.D degree. At present, Professor Yang holds concurrent positions as the Dean of College of Mechanical Science and Engineering in Jilin University, Director of Mechanical Engineering Society of jilin province.In 1999 and 2001, e has published more than 70 papers, of which 20 were compiled into EI and 8 were compiled into SCI. He has gained 4 progress prize in science and technology.

Baichao Wang Male, corresponding author of the paper, born in 1980 doctoral candidate and graduated in 2007, and received his Master Degree in mechanical manufacture \& automation at Jilin University. He is now engaged in the study and research of design and process of equipment system. He has published 8 papers, and taken on 7 military defense project. At present, his research interest is spiral bevel gear.

This article is an extended and modified version of a paper presented at the International Conference on Mechanical Engineering, Automation and Material Science (MEAMS2012), held 22-23 December 2012, Wuhan, China. Received 20 April 2013. Published as resubmitted by the authors 01 May 2013. 